\title{
Conciencia pragmática y afinidad lingüística: análisis de cortesía verbal en correos electrónicos de estudiantes universitarios españoles e italianos
}

\author{
Pragmatic Awareness and Linguistic Affinity: \\ Analysis of Verbal Politeness in E-mails of \\ Spanish and Italian University Students
}

Pilar Robles Garrote

Centro Lingüístico de Ateneo

Università di Padova

Via Venezia 16. Padova (PD), 35131. Italia

pilar.robles@unipd.it

Orcid ID 0000-0001-7586-6923

Resumen: La afinidad lingüística suele representar un gran apoyo a nivel gramatical; sin embargo, esto no siempre ocurre en el plano pragmático, pues este se rige por convenciones culturales cuyas divergencias pueden poner en peligro la eficacia comunicativa. El objetivo del presente artículo es aportar datos empíricos que pongan de manifiesto la importancia del desarrollo de una conciencia pragmática en el estudio de lenguas afines; para ello, se presenta un estudio que analiza las estrategias de cortesía verbal en un corpus de correos electrónicos de petición en el que estudiantes universitarios españoles e italianos realizan peticiones a sus profesores. Los resultados revelan que, pese a la gran afinidad lingüística y cultural, los correos electrónicos del contexto académico español y el italiano presentan tendencias distintas en la selección de estrategias de cortesía verbal y que las características pragmáticas de la L1 se reflejan en las producciones en L2.

Palabras clave: Cortesía verbal. Correos electrónicos. Conciencia pragmática. Lenguas afines. Sociopragmática.
RECIBIDO: 13 DE ENERO DE 2019 ACEPTADO: 17 DE JUNIO DE 2019
Abstract: A high level of linguistic affinity usually results in higher commonality in the grammatical plane. However, this does not always occur in the pragmatic plane because of cultural conventions whose divergences can endanger communicative effectiveness. The objective of this article is to explain with empirical data the importance of the development of a pragmatic awareness in the study of related languages. For this purpose, verbal politeness strategies are analyzed in a sample of emails in Spanish and Italian in which university students have made requests to their professors. The results indicate that, despite the great linguistic and cultural affinity, emails from Spanish and Italian academic contexts show different tendencies in the selection of verbal politeness strategies and that the pragmatic characteristics of $L 1$ are carried over to $L 2$.

Keywords: Verbal Politeness. E-mails. Pragmatic Awareness. Related Languages. Sociopragmatics. 


\section{COMPETENCIA PRAGMÁTICA Y ANÁLISIS CONTRASTIVO}

as convenciones sociopragmáticas determinan el uso de los diferentes recursos lingüísticos y la interpretación de las intenciones comunicativas de estos en diferentes contextos. La competencia pragmática recoge la adecuación de estas convenciones al ámbito en el que se desarrollan y constituye un elemento esencial en las relaciones interpersonales, pues las carencias en este sentido pueden provocar malentendidos en la comunicación, especialmente cuando los interlocutores pertenecen a culturas diferentes.

En el aula de lenguas extranjeras, el profesor es el primero que ha de ser consciente de las normas que rigen su propia lengua, tan difíciles de identificar, dada la falta de materiales dedicados a este fin. Así, las preguntas de los alumnos sobre cuestiones pragmáticas frecuentemente suelen obtener respuestas que apelan a las sensaciones personales de quien las responde o a la "artificialidad" de los enunciados, concepto difícil de comprender para el alumno si este carece de referentes claros que le sirvan de guía. En ese mismo sentido, Blum-Kulka asevera:

Los profesores necesitan estar muy atentos al fenómeno pragmático de la utilización de la lengua; a menudo descubrimos fenómenos de nuestra lengua nativa al observar los errores pragmáticos realizados por hablantes no nativos. En clase, cuando un estudiante dice algo que no incluye un error gramatical pero que sencillamente "no suena bien", o que resulta diferente de lo que quería decir, necesitamos poder comprender qué es lo que ha ido mal. El análisis acumulativo de tales errores pragmáticos podría ayudar al profesor a descubrir normas pragmáticas sobre su lengua nativa. (165)

El cotejo de nuestra lengua y nuestra cultura con otras lenguas y culturas es, la mayoría de las veces, el único modo de comprender la importancia de las normas sociales y culturales que rigen la selección de las formas lingüísticas creando los diferentes estilos de interacción propios de una lengua (Galindo). Los contrastes son necesarios para la identificar explícitamente las analogías y divergencias existentes en diferentes culturas y proporcionan herramientas didácticas de gran utilidad, pues el análisis y la reflexión de modelos contrastados permiten a los estudiantes obtener las herramientas necesarias para lograr un intercambio comunicativo eficaz con otras culturas.

Por otra parte, el contraste de las convenciones pragmáticas de otras culturas con las propias, además de proporcionar recursos para gestionar conflictos vinculados a la comunicación intercultural, invita a la reflexión sobre la propia 
identidad social y sobre las interacciones comunicativas y su eficacia en diferentes contextos culturales. Del mismo modo, permite comprender mejor los mecanismos de interacción en otras culturas y ayuda a fomentar actitudes de solidaridad y tolerancia, imprescindibles en una sociedad cada vez más multicultural.

Por otro lado, el enfoque contrastivo resulta particularmente aconsejable cuando la distancia entre la L1 y la L2 es poca y es percibida como tal, como es el caso del español y el italiano, dos lenguas cuya semejanza puede ser engañosa y, a menudo, dificulta la identificación de las diferencias entre ambas (Calvi 2004). ${ }^{1}$

\section{LA CONCIENCIA PRAGMÁTICA EN LA COMUNICACIÓN INTERCULTURAL}

Lo expuesto anteriormente pone de manifiesto la necesidad del desarrollo de una conciencia pragmática que permita reflexionar sobre la diferencia de los códigos pragmáticos en diferentes culturas, y que permita reconocer si en un enunciado coinciden la intención del emisor y la percepción del interlocutor. Sin embargo, para crear una conciencia pragmática, es preciso extrapolar al plano consciente las estrategias de la propia cultura para poder contrastarlas con las de la cultura meta, especialmente cuando la similitud entre ambas dificulta la identificación de las diferencias, como suele ocurrir en las lenguas afines, como el español y el italiano. La percepción de poca distancia entre estas dos lenguas favorece la transferencia positiva, pero también las interferencias, a menudo difíciles de identificar debido a la coincidencia parcial de algunos aspectos en las dos comunidades o la falta de conciencia de estos fenómenos por parte de los hablantes (Calvi 1995). Como ejemplo de esta coincidencia parcial, Calvi hace referencia precisamente a las convenciones que rigen las reglas de la cortesía en las culturas italiana y española, reflejadas en el uso de las formas alocutivas, la adopción de determinados estilos o registros, el uso de las fórmulas retóricas en la comunicación escrita y los diversos fenómenos paralingüísticos.

No hay duda de que el amplio material lingüístico compartido entre el español y el italiano favorece la transferencia positiva, pero la cercanía lingüística se convierte en un problema y genera errores e incomprensión cuando el alumno pierde el límite o la conciencia de distancia entre las dos lenguas (Ainciburu). Tratándose de lenguas y culturas afines, el alto número de coincidencias a nivel lingüístico hace que el hablante tienda a confiar excesiva-

1. Calvi $(1995 ; 2004)$ utiliza el término percepción de distancia para referirse a la hipótesis que formula el hablante sobre la proximidad tipológica entre el código lingüístico de su lengua materna y el de la lengua meta. 
mente en la similitud lingüística; sin embargo, el alto grado de afinidad dificulta la identificación de las divergencias que provocan ambigüedades entre ambas lenguas o cambios de significado de un mismo enunciado. Así, ante un enunciado identificable en ambas lenguas pero con un significado diferente, estas diferencias frecuentemente suelen pasar inadvertidas, teniendo como consecuencia la distorsión en la interpretación del mensaje.

La cercanía de las lenguas afines frecuentemente afecta también a la interpretación de algunas estrategias pragmáticas difíciles de evidenciar sin un análisis contrastivo. En este tipo de estrategias, la percepción de mayor o menor distancia lingüística puede inducir a conclusiones desacertadas y dar lugar a interpretaciones erróneas, pues el uso de las diferentes estrategias suele atender a rasgos pragmáticos fuertemente ligados al contexto sociocultural. Por ejemplo, el uso de estrategias de petición directa en un contexto en el que las convenciones culturales requieren otro tipo de estrategias puede ocasionar daños irreparables en la imagen del emisor de la petición, quien, sin ser consciente de ello, sería considerado un maleducado o grosero por resultar demasiado directo. En este sentido, Nuzzo y Rastelli ponen en evidencia la necesidad de la conciencia pragmática en el aprendizaje de lenguas afines comparando la diversa percepción sobre el grado de cortesía de la misma estrategia de petición en el español de Uruguay y en italiano:

Nello spagnolo dell'Uruguay le richieste a basso livello d'imposizione formulate all'indirizzo di un interlocutore il cui potere relativo è analogo a quello del parlante prevedono generalmente l'uso del verbo querer al presente indicativo (quiero) piuttosto che al condizionale quisiera (Márquez Reiter, 2000: 40), mentre in italiano l'indicativo voglio è avvertito come scortese nella maggior parte delle situazioni di richiesta. Un apprendente uruguaiano d'italiano L2 che pure conoscesse la possibilità di mitigare la richiesta con l'uso del condizionale potrebbe non disporre della competenza sociopragmatica necessaria per adottare questa strategia nelle situazioni che lo richiedono. (22)

Por otra parte, los problemas en la comunicación intercultural no solamente pueden afectar a los no nativos, pues la diversidad de percepción y de interpretación de las mismas estrategias la podemos encontrar incluso entre hablantes de una misma lengua, pero con códigos pragmáticos distintos, que no son conscientes de esta variación ni de su alcance. Así, las diferencias en los matices culturales pueden provocar distorsiones comunicativas por la falta de 
conciencia pragmática también entre hablantes que comparten idioma, pero no costumbres ${ }^{2}$ (Robles 2016, 332).

En efecto, en una interacción comunicativa entre hablantes de lenguas muy distantes, los interlocutores tienen pocos puntos de conexión en los que apoyarse e, inevitablemente, la elaboración del discurso implica una gran atención, pues es preciso llevar al plano consciente tanto las estrategias comunicativas, lingüísticas y pragmáticas, como el efecto que estas producen en el interlocutor de la otra cultura. Sin embargo, cuando el código lingüístico no representa ningún obstáculo en la comunicación entre los interlocutores, se suele pasar por alto que también han de considerarse los códigos pragmáticos, diferentes en cada cultura; estos últimos determinan la selección de las estrategias para las diferentes funciones de la lengua y delimitan la percepción de sus enunciados y su adecuación al contexto comunicativo.

En este sentido, en los últimos años, diversas investigaciones empíricas enfocadas en el análisis de la cortesía verbal recogen diferencias en la selección de las estrategias pragmáticas en varias culturas hispanohablantes. Por ejemplo, algunos estudios revelan que los hablantes chilenos tienden claramente a utilizar estrategias de cortesía negativa o mitigadora (López Díaz; Toledo Vega), en contraposición con otras variantes del español, que presentan más rasgos de la cortesía positiva o valorizante, como la mexicana (Nicholls), la venezolana (César Vera) o la argentina (Hauge). Por otra parte, cuando se trata de contextos formales de interacción escrita, en la variedad de español peninsular son frecuentes tanto las estrategias valorizantes como las mitigadoras (Betti; Jimeno Patrón; Contreras; Robles 2014, 2016, 2017).

Como vemos, la conciencia pragmática no se refiere a la diferencia idiomática entre los interlocutores, sino a las diferencias culturales y los efectos de los recursos comunicativos empleados. De este modo, parece evidente que esta capacidad de introspección pragmática es decididamente necesaria, más aún cuando resulta difícil identificar los matices culturales implicados en las estrategias comunicativas, como puede ocurrir entre hablantes de una misma lengua o de lenguas afines.

2. A modo de ejemplo, Steele, comparando el español mexicano y el peninsular, señala que los imperativos sin atenuación en las peticiones son vistos como bastantes descorteses por los mexicanos pero no por los españoles y, por el contrario, para los mexicanos el diminutivo es más cortés, mientras que los españoles lo consideran más irónico y relacionado con las interpretaciones negativas. Esta diferente percepción tiene como resultado que los mexicanos ven a los españoles como muy directos y groseros y estos últimos consideran que los mexicanos son excesivamente amables y no muy claros. 


\section{Metodología}

\section{Preguntas de investigación}

El objetivo del presente estudio es aportar datos empíricos que pongan de manifiesto la importancia del desarrollo de una conciencia pragmática en el estudio de lenguas afines. Para ello, se expone un análisis pragmático de carácter cualitativo de un corpus de correos electrónicos en español e italiano que gira en torno a las siguientes preguntas de investigación:

- ¿Qué estrategias de cortesía se utilizan en los correos electrónicos en L1 analizados? ¿Existen diferencias en las estrategias de cortesía utilizadas en los correos electrónicos de españoles e italianos?

- ¿Qué estrategias de cortesía se manifiestan en los correos electrónicos redactados en L2? ¿Son las mismas que utilizan los hablantes nativos?

\section{Características del corpus}

En el presente estudio empírico se expone una investigación de carácter cualitativo realizada a partir del análisis de un corpus de 256 correos electrónicos del ámbito académico. ${ }^{3} \mathrm{El}$ corpus se generó a partir de dos situaciones simuladas de petición a un profesor redactadas por 160 estudiantes universitarios italianos y españoles (96 italianos y 64 españoles) y se dividió creando cinco grupos segmentados del siguiente modo: 96 correos electrónicos en italiano L1 (en adelante @IL1), 64 en español L1 (en adelante @EL1), 64 en español L2 (en adelante @EL2), subdividido a su vez en tres subgrupos de 32 muestras cada uno según el nivel de competencia del Marco común europeo de referencia para las lenguas (MCER): B1, B2 y C1.

A fin de neutralizar los aspectos que pudieran afectar al uso de las estrategias pragmáticas, se intentó controlar los tres factores de los que, según Brown y Levinson, depende el nivel de cortesía: la relación de poder social con respecto al interlocutor (relación jerárquica asimétrica de mayor poder del destinatario: alumno-profesor), la distancia social (el profesor es un interlocutor conocido y de trato habitual que tiene la misma edad en los dos correos) y el nivel de imposición de la petición (todas las consignas solicitan al profesor algo que se sale de la norma establecida, estableciendo una petición de alta imposición).

3. El corpus del estudio empírico al que se refiere el presente artículo forma parte de una investigación de mayor envergadura enmarcada en la tesis doctoral inédita de Robles (2017). 


\section{Diseño}

A fin de describir y comparar las estrategias de cortesía verbal en la interacción escrita de estudiantes universitarios en correos electrónicos del ámbito académico en italiano L1 y español L1/L2, se cotejaron las muestras del corpus considerando las siguientes variables:

\begin{tabular}{|c|c|c|c|c|}
\hline & VARIABLES & $\begin{array}{l}\text { DEFINICIÓN } \\
\text { CONCEPTUAL }\end{array}$ & $\begin{array}{l}\text { DEFINICIÓN } \\
\text { OPERACIONAL }\end{array}$ & CATEGORÍAS \\
\hline \multirow{2}{*}{ 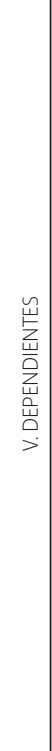 } & \multirow{2}{*}{$\begin{array}{l}\text { Estrategias } \\
\text { de cortesía } \\
\text { verbal }\end{array}$} & \multirow{2}{*}{$\begin{array}{l}\text { Conjunto } \\
\text { de estrategias } \\
\text { conversacionales } \\
\text { destinadas } \\
\text { a evitar o mitigar } \\
\text { las tensiones } \\
\text { cuando el hablante } \\
\text { se enfrenta } \\
\text { a un conflicto } \\
\text { creado entre } \\
\text { sus objetivos y los } \\
\text { del destinatario }\end{array}$} & \multirow{2}{*}{$\begin{array}{l}\text { Estrategias para } \\
\text { mitigar el acto de } \\
\text { habla de la petición } \\
\text { en la interacción } \\
\text { escrita de carácter } \\
\text { asíncrono }\end{array}$} & $\begin{array}{l}\text { Estrategias valorizantes } \\
\text { - Interés/cercanía hacia el destinatario } \\
\text { - Enunciados o marcadores interjectivos } \\
\text { - Puntos en común/acuerdo } \\
\text { - Identidad grupal } \\
\text { - Exagerar/enfatizar } \\
\text { - Apelar a la reciprocidad/prometer } \\
\text { - Ser optimista } \\
\text { - Dar razones } \\
\text { - Satisfacer los deseos del receptor }\end{array}$ \\
\hline & & & & $\begin{array}{l}\text { Estrategias mitigadoras } \\
\text { - Mostrar pesimismo } \\
\text { - Dar opciones para no actuar } \\
\text { - Minimizar la imposición } \\
\text { - Mostrar deferencia } \\
\text { - Pedir disculpas } \\
\text { - Impersonalizar al receptor o al emisor } \\
\text { - Nominalizar } \\
\text { - Agradecer } \\
\text { - Mostrar deuda de agradecimiento }\end{array}$ \\
\hline \multirow{2}{*}{ 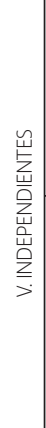 } & Lengua & $\begin{array}{l}\text { Sistema lingüístico } \\
\text { o de comunicación } \\
\text { verbal }\end{array}$ & $\begin{array}{l}\text { Lengua o variante } \\
\text { lingüística en L1 } \\
\text { o L2 utilizada por } \\
\text { los informantes } \\
\text { en las muestras }\end{array}$ & $\begin{array}{l}\text { - Italiano L1 } \\
\text { - Español L1 } \\
\text { - Español L2 }\end{array}$ \\
\hline & $\begin{array}{l}\text { Nivel de } \\
\text { competencia } \\
\text { lingüística en } \\
\text { español }\end{array}$ & $\begin{array}{l}\text { Categorización } \\
\text { según el MCER } \\
\text { del dominio } \\
\text { de las destrezas } \\
\text { lingüísticas en } \\
\text { lengua española }\end{array}$ & $\begin{array}{l}\text { Nivel de dominio } \\
\text { de la interacción } \\
\text { escrita en español } \\
\text { L2 }\end{array}$ & $\begin{array}{ll}- & \text { B1 } \\
- & \text { B2 } \\
- & \text { C1 }\end{array}$ \\
\hline
\end{tabular}

Figura 1. Cuadro de operacionalización de las variables

4. Definición del Diccionario de términos clave de ELE. 
Para el análisis se utilizó el modelo para el estudio de la cortesía verbal presentado en Robles (2014), basado en una adaptación de la taxonomía de Brown y Levinson, con los ajustes oportunos para el estudio de la cortesía en peticiones por correo electrónico. En el modelo propuesto se analiza la presencia, ausencia y frecuencia de dieciocho estrategias de cortesía verbal: nueve valorizantes y nueve mitigadoras (ver figura 1). A modo de ejemplo de la implementación de este modelo de análisis, se presenta una categorización esquemática de las estrategias encontradas en uno de los correos electrónicos.

Estimado\{1\} Antonio\{2\}:

Te \{3\} escribo porque el plazo de entrega del proyecto final del máster termina este martes pero no me va a ser posible\{4\} terminar a tiempo el trabajo. Estas dos últimas semanas he tenido problemas familiares que me han impedido dedicar el tiempo necesario al máster \{5\}. Sé que los asuntos personales no deberían interferir con los académicos, pero no siempre podemos con todo $\{6\}$. ¿ Sería $\{7\}$ posible \{8\} que te entregara el trabajo el viernes a primera hora? Muchas gracias $\{9\}$

\begin{tabular}{l|l}
\multicolumn{1}{c|}{ EstrateGiaS PRAGMátICAS } & TIPO DE CORTESía \\
\hline$\{1\}$ Mostrar deferencia: saludo formal & mitigadora \\
\hline$\{2\}$ Cercanía hacia el destinatario: nombre de pila & valorizante \\
\hline$\{3\}$ Cercanía hacia el destinatario: tuteo & valorizante \\
\hline$\{4\}$ Nominalizar & mitigadora \\
\hline$\{5\}$ Dar razones & valorizante \\
\hline$\{6\}$ Puntos en común/tratar de mostrar acuerdo & valorizante \\
\hline$\{7\}$ Minimizar la imposición: condicional & mitigadora \\
\hline$\{8\}$ Dar opciones para no actuar: ser + posible & mitigadora \\
\hline$\{9\}$ Agradecer & mitigadora \\
\hline
\end{tabular}

\section{Procedimiento}

El presente estudio empírico se llevó a cabo teniendo en cuenta el siguiente procedimiento: en primer lugar, se consolidó el instrumento de recogida de datos y se llevó a cabo un proceso de validación de las consignas de los correos 
electrónicos de petición que conformarían el corpus. La validación se realizó mediante el método de juicio de expertos, consistente en la consulta a diversos investigadores especialistas en el objeto de análisis con el fin de obtener un peritaje técnico exhaustivo que permitiera realizar las modificaciones oportunas, garantizando la validez y fiabilidad necesarias para poder utilizarlo en la investigación empírica. ${ }^{5}$

Una vez concluida la validación de las consignas, se procedió a la elaboración del corpus en L1 y L2 que serviría como soporte central de la presente investigación y a la posterior clasificación de los datos empíricos. En primer lugar, se recogieron los @IL1 y @EL2 redactados por los alumnos italianos y, en un segundo momento, se recogieron los @EL1 de los estudiantes españoles, que debían ser redactados siguiendo las mismas consignas que sus homólogos italianos.

Posteriormente, se realizó el etiquetado del corpus y se analizaron las producciones escritas para explicitar las estrategias de cortesía verbal encontradas en las muestras en L1 del corpus. Tras identificar las características pragmáticas utilizadas en todas las producciones, se efectuó su clasificación. El procesamiento de los datos se realizó mediante un recuento de frecuencia de las diferentes categorías de cortesía verbal establecidas en la operacionalización de las variables y, una vez terminada la clasificación y recuento de todos los datos empíricos, se cuantificó el número total de ocurrencias y los porcentajes de la frecuencia de uso de las estrategias pragmáticas.

Por último, se compararon las estrategias utilizadas en los correos electrónicos en L2 de los aprendientes italófonos, confrontándolas con las utilizadas en sus propias producciones en L1 y con las de español L1. También se relacionaron los resultados con los datos relativos a las competencias lingüísticas de los alumnos italianos para comprobar las estrategias utilizadas en cada nivel, comparándolas con las producciones en L1 y cotejando los resultados con los obtenidos en estudios anteriores.

\section{Validez de muestras no reales en el análisis pragmático de la interacción escrita}

Como se ha señalado, los datos empíricos de este trabajo de investigación proceden de un corpus de correos electrónicos de petición creados a partir de dos situaciones comunicativas comunes en el ámbito académico. Algunos autores,

5. Para mayor información sobre la validación por juicio de expertos, ver Robles/Rojas. 
como Beebe/Cummings, Mackey/Gass o Turnbull, resaltan la importancia de analizar producciones reales y evitar el uso de simulaciones en el análisis de los actos de habla en el discurso oral. Ante la convicción de estos lingüistas de que en el campo de la sociolingüística y la pragmática solo los estudios sobre lenguaje natural son válidos, Doquin de Saint Preux sostiene que dicha reserva impide frecuentemente desarrollar investigaciones de gran envergadura, necesarias para aportar datos cuantitativos. La autora recuerda que muchas veces para obtener suficientes datos en la investigación es preciso forzar y controlar el discurso con el que se trabaja para recoger datos de producciones o interpretaciones y actitudes frente a un discurso elegido:

El trabajo del investigador en sociolingüística y pragmática consiste, entonces, en encontrar técnicas para trabajar con un discurso que sea lo más representativo posible de un discurso natural, usando técnicas de elicitación y creando los contextos más naturales posibles, tomando en cuenta las variables externas que necesita controlar y usando técnicas para probar la similitud con un lenguaje natural. (58)

No obstante, en el caso de la interacción escrita por correo electrónico, la creación de una muestra real no dista mucho de una simulación, pues el medio escrito en ambos casos permite un mayor control sobre el discurso emitido y la posibilidad de efectuar cambios en el mensaje antes de entregárselo al receptor.

Asimismo, es preciso señalar que las muestras reales en L1 también pueden presentar fallos pragmáticos y alejarse de las características aceptables en una interacción de estas características en el contexto académico, como muestran algunos estudios empíricos (Dumitrescu; Nikleva; Nikleva/Núñez), por lo que, del mismo modo, se podría poner en duda la fiabilidad de su uso como modelo de lengua de referencia con el que poder cotejar las muestras en L2. Es cierto que en los correos electrónicos simulados los informantes son conscientes de que sus producciones serán analizadas o evaluadas y esto podría condicionar su modo de escribir y las estrategias pragmáticas utilizadas; sin embargo, consideramos que el hecho de que los participantes se sientan evaluados resulta un factor positivo en este caso, pues, sabiendo de antemano que sus producciones serán examinadas, tratarían de utilizar recursos o estrategias que consideren adecuadas en el contexto simulado.

Además, uno de los objetivos del presente trabajo es comprobar si, en las producciones en L2 de los aprendientes italófonos, los estudiantes tienen en 
cuenta las características pragmáticas de la cultura meta o si únicamente realizan una traducción lingüística, reproduciendo en sus escritos las características pragmáticas de su L1. Así, la dificultad de encontrar situaciones reales de idénticas características, que permitan observar el comportamiento pragmático de un sujeto ante la misma situación y en dos lenguas distintas, hace que sea necesario provocar la interacción comunicativa mediante simulacros dirigidos a la creación de producciones escritas comunes en la cotidianeidad universitaria actual. De este modo, la simulación de situaciones de interacción escrita en el contexto académico resulta un método válido en este caso.

\section{RESULTADOS}

Abordando una visión global de los datos empíricos, los resultados reflejan diferencias significativas en la selección de los tipos de estrategias de cortesía verbal entre los dos grupos de L1, pues, mientras los españoles intercalan estrategias de cortesía mitigadora y valorizante, los italianos mantienen un claro predominio de la cortesía mitigadora que también se transfiere a sus producciones en L2 (ver figura 2).
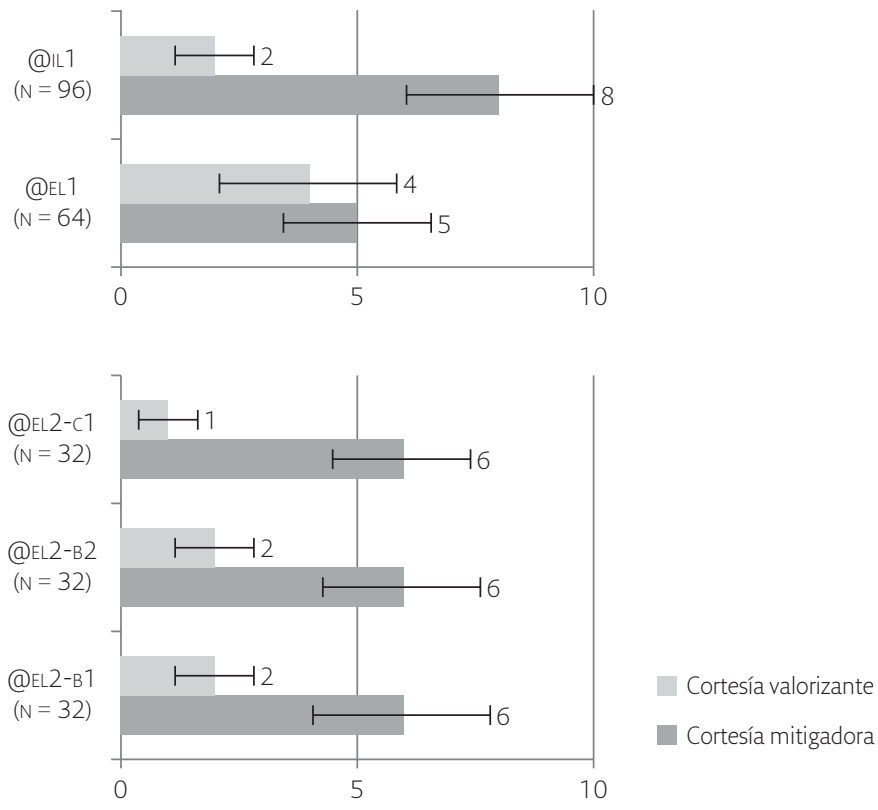

Figura 2. Frecuencia de cortesía valorizante y mitigadora en L1 y L2 
Además, en las muestras en L2 no se observan diferencias significativas en el uso de las estrategias mitigadoras en los diferentes niveles, manteniéndose estable en todos ellos, lo que parece indicar que la transferencia del uso de las estrategias de cortesía verbal no se reduce con el dominio de la competencia lingüística.

Las muestras de los hablantes de español peninsular contienen un porcentaje similar de estrategias valorizantes y mitigadoras que concuerda con los resultados del análisis de correos electrónicos de Jimeno Patrón, Betti, y Robles (2014). Estos datos confirman que en la cultura española, en los correos electrónicos con una relación de asimetría jerárquica entre los interlocutores, el contexto de interacción comunicativa exige el uso de ciertas estrategias mitigadoras que se suman a las valorizantes. Estos resultados, en los que presenta un uso equitativo de estrategias valorizantes y mitigadoras en los @EL1, hacen patente la inadecuación de catalogar categóricamente al español como lengua de cortesía positiva, como afirma Fernández Amaya (17), más aún teniendo en cuenta la amplia diversidad pragmática que abarcan las diferentes culturas de habla hispana, como ratifican los estudios citados anteriormente.

Asimismo, los resultados en italiano L1 también reafirman los obtenidos en Robles (2014) con respecto a los correos electrónicos académicos de relación jerárquica asimétrica y contrastan con las aseveraciones de Sifianou y Haverkate, quienes afirman que las culturas mediterráneas tienden a la cortesía positiva, pues en el ámbito académico, las muestras en italiano muestran una elevada cantidad de estrategias mitigadoras, muy superior a la de los @EL1. En efecto, pese a que la cultura española y la italiana son de origen mediterráneo y a su gran afinidad tanto a nivel cultural como lingüístico, a menudo el estilo retórico de ambas presenta divergencias en la frecuencia de uso de los recursos lingüísticos y estrategias pragmáticas compartidas por estas dos culturas, especialmente en los registros formales, como también reflejan los resultados acerca de las estrategias pragmáticas utilizadas en correos electrónicos de registro formal e informal del estudio de Robles (2014).

\section{Estrategias de cortesía verbal en español e italiano L1}

La figura 3 expone una confrontación de los resultados de cortesía valorizante y mitigadora en español e italiano L1, donde aparecen sombreadas las estrategias de mayor presencia en el corpus analizado. 


\begin{tabular}{|c|c|c|c|}
\hline & & $\begin{array}{c}@ E \text { E1 } \\
(\mathrm{N}=64)\end{array}$ & $\begin{array}{c}@ @ \mid L 1 \\
(N=96)\end{array}$ \\
\hline \multirow{9}{*}{ 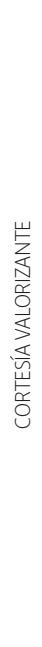 } & Mostrar interés o cercanía hacia el destinatario & $73.4 \%$ & $5.2 \%$ \\
\hline & Usar marcadores interjectivos & $1.5 \%$ & $0 \%$ \\
\hline & Presuponer puntos en común/buscar acuerdo & $48.4 \%$ & $18.7 \%$ \\
\hline & Mostrar identidad grupal & $20.3 \%$ & $34.3 \%$ \\
\hline & Enfatizar/exagerar & $20.3 \%$ & $5.2 \%$ \\
\hline & Apelar a la reciprocidad/prometer & $0 \%$ & $0 \%$ \\
\hline & Asumir que el destinatario será cooperativo & $7.8 \%$ & $14.5 \%$ \\
\hline & Dar razones & $96.8 \%$ & $92.7 \%$ \\
\hline & Satisfacer los deseos del receptor & $18.7 \%$ & $7.2 \%$ \\
\hline \multirow{9}{*}{ 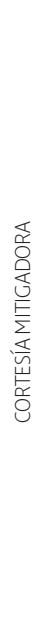 } & Mostrar pesimismo & $14 \%$ & $29.1 \%$ \\
\hline & Dar opciones para no actuar & $65.6 \%$ & $83.3 \%$ \\
\hline & Minimizar la imposición/usar mitigadores & $90.6 \%$ & $93.7 \%$ \\
\hline & Ser respetuoso/Mostrar deferencia & $45.3 \%$ & $100 \%$ \\
\hline & Pedir disculpas & $21.8 \%$ & $16.6 \%$ \\
\hline & Impersonalizar al receptor o al emisor & $26.5 \%$ & $50 \%$ \\
\hline & Nominalizar & $25 \%$ & $13.5 \%$ \\
\hline & Agradecer & $68.7 \%$ & $70.8 \%$ \\
\hline & Mostrar deuda de agradecimiento & $7.8 \%$ & $3.1 \%$ \\
\hline
\end{tabular}

Figura 3. Estrategias de cortesía valorizante y mitigadora en L1

Como se aprecia en la tabla de la figura 3, la estrategia más utilizada en los @EL1, presente prácticamente en todas las muestras de este grupo, es Dar razones, estrategia valorizante con la que se encuadra la petición en un contexto justificado, y predominante también en los estudios de Nicholls y de Robles (2014). 
La siguiente estrategia de alta frecuencia es mitigadora, Minimizar la imposición/usar mitigadores, para atenuar la fuerza ilocutiva del acto de habla de petición. Tiene una amplia acogida en los dos grupos (90.6 \% en @EL1, $93.7 \%$ en @IL1), en los que se aprecian diversos modos de mitigación, como la modificación del tiempo verbal, los recursos para minimizar la cantidad o la cualidad, como los cuantificadores indefinidos (algún, algo), los recursos léxicos que confieren un efecto atenuador a la petición (rogar, solicitar, conceder, considerar) o las partículas y los adverbios modales (por favor o gentilmente, fórmula habitual en los @IL1).

La siguiente estrategia en orden de presencia entre los @EL1 es valorizante (73.4\%): Mostrar interés o cercanía hacia el destinatario mediante el tuteo o el uso del nombre de pila del interlocutor como apelativo, porcentaje que contrasta significativamente con el bajísimo índice de esta misma estrategia en los @IL1 (5.2\%).

Otras dos estrategias con una presencia considerable en los @ EL1 son Agradecer y Dar opciones para no actuar, frecuentemente mediante construcciones con el verbo poder + infinitivo o la construcción es posible + infinitivo.

La estrategia valorizante Presuponer puntos en común/Buscar acuerdo aparece prácticamente en la mitad de los @EL1 y en un grado muy inferior en los @IL1 (48.8\% en @EL1, 18.7 \% en @IL1) y contempla la exposición de informaciones compartidas y/o el intento de buscar acuerdo o evitar desacuerdo con el interlocutor.

El porcentaje de uso de la estrategia mitigadora Ser respetuoso/Mostrar deferencia se aleja muchísimo en los @IL1, con un índice de presencia bajísimo en el caso de la valorizante, mientras la mitigadora es utilizada por absolutamente todos los participantes italófonos. También aparecen otras estrategias de ambos tipos con un porcentaje menor de presencia, como Impersonalizar al receptor o al emisor, Nominalizar, Pedir disculpas, Mostrar identidad grupal, Enfatizar/Exagerar, Satisfacer los deseos del receptor o Mostrar pesimismo; y estrategias de presencia casi inapreciable como Asumir que el destinatario será cooperativo o Mostrar deuda de agradecimiento.

Los resultados en los @EL1 coinciden, a grandes rasgos, con los de Betti y con los de Contreras Fernández, que ponen de manifiesto que el estilo de muchas de las muestras de los participantes españoles es informal y la relación entre los interlocutores no se percibe como asimétrica, sino como de cercanía, utilizando en ocasiones un vocabulario más característico del registro coloquial. Asimismo, estos resultados también concuerdan en las manifestaciones 
de informalidad y cercanía con los de las muestras de los participantes venezolanos del estudio de César Vera, que a su vez difiere del estilo preferentemente formal y deferente de los participantes chilenos del mismo estudio.

En cuanto a las muestras de los @IL1, destaca la alta presencia de estrategias mitigadoras en detrimento de las valorizantes, que apenas tienen presencia en italiano L1. La característica principal de los @IL1 es la enunciación deferente, que se encuentra en el $100 \%$ de los @ IL1, mientras que la estrategia Ser respetuoso/Mostrar deferencia es utilizada por algo menos de la mitad de los informantes españoles (45.3\%). Esta deferencia se localiza sobre todo en los saludos y despedidas formales de carácter estandarizado, las fórmulas pronominales respetuosas como el tratamiento de usted, o, en el caso del italiano, el uso de la mayúscula en los pronombres personales y adjetivos posesivos (Gentile Professor Rossi, sono uno studente iscritto al master universitario da Lei coordinato).

Este altísimo porcentaje contrasta con la menor presencia en los @EL1 y remarca la diferencia en el tono en ambas culturas en este registro. La siguiente estrategia en frecuencia en las muestras en italiano L1, que también alcanza un altísimo índice de presencia, reflejado prácticamente en todas las muestras, es Minimizar la imposición/usar mitigadores para minimizar la imposición de la petición, como la modificación temporal del verbo con condicional o pretérito imperfecto, los adverbios modales como gentilmente, al igual que en el estudio de Bitonti. En tercer lugar se encuentra Dar razones, estrategia valorizante de elevadísima presencia, y la estrategia mitigadora Dar opciones para no actuar, presente en construcciones con el verbo potere + infinitivo o la construcción se possibile + infinitivo, al igual que los @EL1 (25\% en @EL1, 52 \% en @ IL1), como muestran los ejemplos, y también coincidiendo con los resultados de Bitonti (60), quien señala esta última fórmula como conector pragmático estructuralmente similar a la prótasis de las construcciones condicionales.

Asimismo, también es muy frecuente que aparezcan otros actos de habla como el Agradecimiento (70.8 \% de los @IL1 y 69.7 \% de los EL1), que aparece frecuentemente en la parte final del correo electrónico, como parte de enunciados estandarizados de despedida. En algunas ocasiones aparece en forma de Deuda de agradecimiento, estrategia menos utilizada por ambos grupos (7.8 \% en @EL1 y $3.1 \%$ en @IL1), o de forma combinada con la anterior, reforzando la intensidad de este acto de habla.

La estrategia Impersonalizar al emisor o al receptor aparece en la mitad de las muestras en italiano, mientras en el grupo de español supera ligeramente 
la cuarta parte (50\% en @IL1, $26.5 \%$ en @EL1). Esta estrategia también suele ir ligada a la construcción ser posible + infinitivo, de la estrategia Dar opciones para no actuar.

Las estrategias con un mayor porcentaje son mitigadoras; sin embargo, también se aprecia el uso de otras estrategias de ambos tipos con un índice más bajo de presencia, como Mostrar identidad grupal, presente en menor medida en los @EL1 (34.3\% en @ $\mathrm{IL}_{\mathrm{IL}} 1,20.3 \%$ en @ $\left.\mathrm{EL}_{1}\right)$, y se encuentra frecuentemente en la autoidentificación del emisor del correo electrónico (Soy Victor Álvarez, de primero de Traducción e Interpretación).

La estrategia Mostrar pesimismo se manifiesta con partículas adverbiales como purtroppo, tanto al principio como al final de la frase, coincidiendo una vez más con Bitonti, quien señala que la función asignada a este adverbio es de tipo interaccional y solo sirve para expresar el estado de ánimo del hablante que modula, reforzándolo, el valor semántico de la proposición.

Estrategias de menor índice de presencia son Presuponer puntos en común/ Buscar acuerdo, Pedir disculpas, Asumir que el destinatario será cooperativo, Nominalizar; y estrategias de presencia casi inapreciable como Satisfacer los deseos del receptor, Enfatizar/Exagerar, Mostrar interés o cercanía hacia el interlocutor o Mostrar deuda de agradecimiento.

Otra diferencia considerable es la percepción de la intensidad en el uso de la estrategia Exagerar/Enfatizar, que presenta un 20.3 \% en los @EL1, mientras apenas tiene presencia en los @IL1 (5.2\%). Respecto a esta estrategia, se ha de tener en cuenta la diferencia en la carga enfática de un mismo término, aparentemente afín en el plano semántico, en español e italiano. Por ejemplo, la expresión sono mortificato/a, frecuente en la lengua italiana para expresar disculpa (è proprio per questo che sono mortificata nel doverle chiedere...) que se podría traducir como "lo siento muchísimo", provocaría un efecto de mucha mayor intensidad en un mismo contexto en España, pues la expresión "estoy mortificado/me mortifica" en este país implicaría máxima aflicción por parte del emisor y resultaría excesiva en una petición de prórroga de un trabajo académico.

Coincidiendo con el estudio de Betti, tanto los @EL1 como los @IL1 concuerdan en el uso del condicional y el imperfecto de cortesía, las fórmulas de saludo, despedida y agradecimiento formales, así como las estrategias que muestran deferencia hacia el interlocutor, con una presencia mucho mayor en los @IL1, que también suma a las estrategias citadas el uso de la mayúscula en los pronombres. Asimismo, concuerdan en el uso de fórmulas para pedir disculpas, también presentes en los resultados de Contreras Fernández. 
En ninguno de los dos grupos lingüísticos se consideran las estrategias Apelar a reciprocidad/prometer y Uso de marcadores interjectivos (tan solo aparece en una de las muestras de @EL1), que parecen poco apropiadas para realizar una petición por correo electrónico a un profesor. Acerca de esta última estrategia, Betti coincide con estos resultados, señalando que "por lo que atañe al uso de emoticones, lo que se nota en los datos recogidos es que no está tan generalizado como varios estudios indican" (83). Esto difiere de la discusión de resultados del estudio de López Cordero, quien señala que en su corpus de correos electrónicos a un profesor los emoticonos compensan la falta de comunicación no verbal imitando las expresiones faciales y las emociones con el objetivo de vencer las limitaciones de tener que comunicarse solo en forma de texto. Con respecto a esta valoración, consideramos que para poder utilizar este tipo de estrategias tendría que haber una cierta proximidad entre los interlocutores, que, a priori, no suele concordar con la asimetría docente-discente en el ámbito universitario.

Estrategias de cortesía verbal de italófonos en español L2

En la figura 4 se presentan los resultados en L2, donde las estrategias de cortesía verbal más utilizadas aparecen sombreadas.

\begin{tabular}{|c|c|c|c|c|}
\hline & & $\begin{array}{c}B 1 \\
(N=32)\end{array}$ & $\begin{array}{c}B 2 \\
(N=32)\end{array}$ & $\begin{array}{c}C 1 \\
(N=32)\end{array}$ \\
\hline \multirow{9}{*}{ 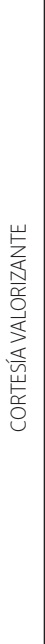 } & Mostrar interés o cercanía hacia el destinatario & $21.8 \%$ & $12.5 \%$ & $0 \%$ \\
\hline & Usar marcadores interjectivos & $0 \%$ & $0 \%$ & $0 \%$ \\
\hline & Presuponer puntos en común/buscar acuerdo & $6.2 \%$ & $18.7 \%$ & $6.2 \%$ \\
\hline & Mostrar identidad grupal & $37.5 \%$ & $31.2 \%$ & $34.3 \%$ \\
\hline & Enfatizar/exagerar & $3.1 \%$ & $0 \%$ & $0 \%$ \\
\hline & Apelar a la reciprocidad/prometer & $0 \%$ & $0 \%$ & $0 \%$ \\
\hline & Asumir que el destinatario será cooperativo & $0 \%$ & $6.2 \%$ & $0 \%$ \\
\hline & Dar razones & $96.8 \%$ & $100 \%$ & $100 \%$ \\
\hline & Satisfacer los deseos del receptor & $0 \%$ & $0 \%$ & $0 \%$ \\
\hline
\end{tabular}


ROBLES. CORTESÍA VERBAL EN CORREOS ELECTRÓNICOS ESPAÑOLES E ITALIANOS

\begin{tabular}{|c|c|c|c|c|}
\hline \multirow{9}{*}{ 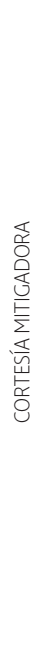 } & Mostrar pesimismo & $9.3 \%$ & $3.1 \%$ & $12.5 \%$ \\
\hline & Dar opciones para no actuar & $75 \%$ & $78.1 \%$ & $75 \%$ \\
\hline & Minimizar la imposición/usar mitigadores & $81.2 \%$ & $81.2 \%$ & $78.1 \%$ \\
\hline & Ser respetuoso/Mostrar deferencia & $100 \%$ & $100 \%$ & $100 \%$ \\
\hline & Pedir disculpas & $6.2 \%$ & $12.5 \%$ & $0 \%$ \\
\hline & Impersonalizar al receptor o al emisor & $28.1 \%$ & $21.8 \%$ & $28.1 \%$ \\
\hline & Nominalizar & $0 \%$ & $0 \%$ & $0 \%$ \\
\hline & Agradecer & $68.7 \%$ & $65.6 \%$ & $50 \%$ \\
\hline & Mostrar deuda de agradecimiento & $0 \%$ & $3.1 \%$ & $3.1 \%$ \\
\hline
\end{tabular}

Figura 4. Estrategias de cortesía valorizante y mitigadora en L2

Si se cotejan los datos empíricos en L1 y L2 (ver figuras 3 y 4), se puede apreciar que la tendencia general en L2 es la de mantener el estilo predominantemente mitigador de los @L1 utilizando un menor número de estrategias que en estos. Sin embargo, se observa que el número de estrategias por muestra en L2 es inferior al utilizado por los mismos participantes en su propia L1. Estos resultados coinciden con los de los estudios de Nicholls y Robles (2014), quienes también observan que, cuando escriben en L2, los informantes utilizan una cantidad inferior de estrategias con respecto a las utilizadas en su L1, número también más bajo que el utilizado por los nativos hispanófonos. Esto puede deberse a la restricción inducida por el menor dominio de la lengua extranjera con respecto a la materna.

$\mathrm{Al}$ igual que en los resultados en $\mathrm{L} 1$, las estrategias más frecuentes son las mitigadoras y su frecuencia no varía en los tres niveles de competencia lingüística. La estrategia por excelencia, siguiendo con la misma línea de los @IL1, también en L2 es Ser respetuoso/Mostrar deferencia, que, al igual que en L1, está presente en absolutamente todas las muestras y también se refleja en fórmulas de tratamiento de respeto, saludos y despedidas de formalidad estandarizada y otras fórmulas para mostrar deferencia. Con respecto a esta estrategia, observamos que la afinidad lingüística hace que, en ocasiones, al trasladar algunas estructuras de deferencia estandarizadas de la L1 a la L2, se produzcan calcos del italiano que no siempre tienen sentido en la lengua meta, 
como es el caso del enunciado "Distintos saludos". Otro ejemplo de interferencia es el uso de las mayúsculas de deferencia en los pronombres y posesivos para mostrar una mayor distinción de respeto hacia el profesor también en L2 (Soy un estudiante de Su curso de Lengua Española y quería pedirLe si Usted...), estrategia inefectiva en español, ya que no cumple el objetivo cortés que pretende el emisor del correo electrónico. También hay que tener en cuenta que un exceso de deferencia puede conferir un sentido irónico al enunciado, distorsionando la única intención de expresar respeto. Así, una fórmula de saludo como "muy señor mío", presente en el corpus analizado y común en los géneros epistolares de formalidad, resulta exagerada en un contexto de conocimiento mutuo con un profesor con el que se habla habitualmente, como el propuesto en los correos electrónicos del presente estudio.

La segunda en frecuencia, presente en casi todas las muestras de los tres niveles, al igual que en los grupos de análisis en L1, es la estrategia valorizante Dar razones (96.8 \% en @EL2-B1, 100 \% en @ EL2-B2, 93.7 \% en @ EL2-C1), estrategia que aparecía en tercer lugar en las L1. La siguiente estrategia con mayor porcentaje de presencia es la mitigadora Minimizar la imposición/usar mitigadores para atenuar la imposición de la petición, cuyos porcentajes de uso en el corpus son similares en los tres grupos de competencia lingüística (81.2\% en @EL2-B1, 81.2 \% en @EL2-B2, 78.1\% en @EL2-C1). La variante más frecuente de esta estrategia es la modificación temporal del verbo (condicional y pretérito imperfecto) y la mitigación mediante recursos léxicos (verbos conceder, considerar o solicitar) y, esporádicamente, los recursos para minimizar la cantidad o cualidad y las partículas y adverbios modales.

La estrategia Dar opciones para no actuar aparece en las construcciones poder + infinitivo y ser + posible + infinitivo, formuladas tanto de modo directo como indirecto, $\mathrm{y}$ tampoco se observan variaciones en cuanto al nivel de competencia lingüística de los autores de los @EL2 (75 \% en @EL2-B1, 78.1\% en @EL2-B2, 75 \% en @EL2-C1).

La estrategia Agradecer se halla en un menor número de muestras, y disminuye en presencia según aumenta el nivel de competencia (68.7 \% en @EL2-B1, $65.6 \%$ en @EL2-B2, $50 \%$ en @EL2-C1). Esta estrategia suele aparecer como enunciado de cierre o como parte de las fórmulas de despedida formal de los géneros epistolares o mediante fórmulas de agradecimiento menos estandarizadas.

La estrategia Impersonalizar al emisor o al receptor se encuentra en un menor número de muestras que en los @IL1 (50 \%) y se asemeja más a los resultados de las muestras en español L1 (26.5 \%): $28.1 \%$ en @EL2-B1, 21.8 \% en 
@EL2-B2, 28.1\% en @EL2-C1. Tampoco en esta estrategia se aprecian variaciones significativas en cuanto a la diferencia de nivel y, como en muchas de las muestras en L1, normalmente va unida a la petición construida mediante la estructura ser + posible + infinitivo, frecuente en los @EL2.

En cuanto al resto de estrategias, destaca el reducido porcentaje de Mostrar pesimismo, algo mayor en las muestras de nivel avanzado (9.3\% en @EL2B1, 3.1\% en @EL2-B2, $12.5 \%$ en @EL2-C1), Pedir disculpas, ausente en el nivel C1 (6.2 \% en @EL2-B1, 12.5 \% en @EL2-B2), Mostrar deuda de agradecimiento, estrategia solo presente en una muestra de $\mathrm{B} 2$ y otra de $\mathrm{C} 1$, y la total ausencia en todos los niveles de Nominalizar.

Con una frecuencia muy inferior, aparecen en el corpus las estrategias Mostrar identidad grupal o Mostrar pesimismo, esta última con una presencia apenas perceptible, pero algo mayor en el nivel $\mathrm{C} 1$. Al igual que en las muestras en L1, la total de ausencia de las estrategias Apelar a reciprocidad/prometer y Uso de marcadores interjectivos muestra que tampoco se consideran a la hora de realizar una petición por correo electrónico a un profesor en ninguno de los niveles de competencia.

En algunas de las estrategias se observa la irregularidad en la presencia en los diferentes niveles, que no parecen seguir una progresión ascendente o descendente, sino que parece más bien una selección de carácter aleatorio, como es el caso de Mostrar interés o cercanía hacia el destinatario, Pedir disculpas o la ausencia o apenas perceptible presencia de otras estrategias presentes en L1 como Nominalizar. Sorprendentemente, el C1, nivel del que se podría esperar un elenco de estrategias más amplio, es precisamente el que menos variedad presenta.

$\mathrm{Al}$ igual que en otras investigaciones centradas en el análisis de correos electrónicos de estudiantes de lenguas extranjeras (Shim; Chen y otros; Tseng, entre otros), estos resultados señalan la presencia de transferencia pragmática en las @EL2, que se aprecia, sobre todo, en la diferencia en el registro del discurso y el uso de las estrategias de cortesía de la L1, que continúan manteniendo un tono formal con predominio de estrategias mitigadoras que difiere del tono informal de las muestras de los nativos españoles.

Los resultados difieren de las afirmaciones de Escandell, quien asevera que la transferencia pragmática se incrementa en los niveles altos, pues en el corpus en L2 analizado se presenta de un modo bastante regular en todos los niveles, habiendo incluso fluctuaciones irregulares entre la selección de algunas estrategias en los distintos niveles, como es el caso de Mostrar interés o cercanía hacia el destinatario o Pedir disculpas. 


\section{CONClusiones}

Los resultados del estudio revelan que los italianos utilizan predominantemente estrategias de cortesía mitigadora, un tono formal, un mayor uso de fórmulas estandarizadas de deferencia y mitigadores para minimizar la imposición de la petición. Los españoles, en cambio, utilizan estrategias atenuadoras combinadas con estrategias valorizantes, que acortan la distancia con el interlocutor y confieren al correo electrónico un mayor tono de informalidad. Con respecto a las muestras en $\mathrm{L} 2$, si bien coinciden en el uso de algunas de las estrategias analizadas por los hablantes de español peninsular, no parece que reproduzcan los mismos patrones pragmáticos que los nativos en el ámbito académico. En efecto, los correos electrónicos en L2 presentan una clara transferencia de las estrategias de cortesía mitigadoras del italiano y un reducido uso de las estrategias valorizantes, al igual que en su L1, y la selección de estrategias no muestra variaciones significativas en función de la competencia lingüística.

De este modo, los resultados ponen de manifiesto que las convenciones de la cortesía verbal en el contexto académico español y el italiano difieren considerablemente y confirman que, con respecto a la cortesía verbal, la proximidad lingüística no resulta un factor determinante para favorecer una transferencia positiva en todos los casos, reafirmando una vez más la necesidad de crear una conciencia pragmática.

Como hemos visto, la afinidad lingüística suele representar un gran apoyo en el plano gramatical, sin embargo, esto no siempre ocurre en el plano pragmático, cuyas convenciones, que no están ligadas a la concordancia lingüística sino a la cultura, pueden coincidir en algunos casos y mostrar grandes divergencias en otros. Cuando dos interlocutores hablan la misma lengua o la distancia lingüística entre ambas es muy corta, se corre el riesgo de no identificar las discordancias, ya que el código lingüístico no supone un obstáculo en la comunicación y, en consecuencia, se tiende a confiar en la semejanza entre los códigos pragmáticos, sin tener en cuenta las diferencias culturales. Así, la falta de conciencia pragmática puede poner en peligro la eficacia comunicativa en la interacción intercultural. Sin embargo, para poder desarrollar una conciencia pragmática, es preciso extrapolar al plano consciente las estrategias de la propia cultura para poder contrastarlas con las de la cultura meta y comprobar si la intención comunicativa y el efecto en el interlocutor coinciden, y, en el caso contrario, poder seleccionar recursos comunicativos que se ajusten 
a las diferencias. Por este motivo, resulta necesario ampliar el panorama investigador en esta área de la sociolingüística con estudios que proporcionen más datos empíricos sobre las estrategias pragmáticas en diferentes culturas. También sería interesante analizar en futuros estudios otras variables que podrían influir en la selección de este tipo de estrategias, como el sexo de los informantes, la edad o la comparación de diversas variedades lingüísticas.

\section{OBRAS CITADAS}

Ainciburu, María Cecilia. Aspectos del aprendizaje del vocabulario: tipo de palabra, método, contexto y grado de competencia en las lenguas afines. Frankfurt am Main: Peter Lang, 2008.

Beebe, Leslie M., y Martha Clark Cummings. "Natural Speech Act Data versus Written Questionnaire Data: How Data Collection Method Affects Speech Act Performance". Speech Acts across Cultures: Challenges to Communication in a Second Language. Eds. Susan M. Gass y Joyce Neu. Berlin: Mouton de Gruyter, 1996. 65-86.

Betti, Silvia. “«jHola profe!»: ¿`son corteses los jóvenes en el correo electrónico? Estudio de mensajes virtuales españoles e italianos". Revista Española de Linguística Aplicada 26 (2013): 67-89.

Bitonti, Alessandro. "L'e-mail nella comunicazione accademica fra pragmatica e coesione testuale". Linguaggio e Apprendimento Linguistico. Metodi e strumenti tecnologici. Studi AItla 4. Eds. Francesca Bianchi y Paola Leone. Bolonia: AItLA, 2016. 51-66.

Blum-Kulka, Shoshana. "Introducción a la pragmática del interlenguaje". La competencia pragmática: elementos linguiisticos y psicosociales. Eds. Jasone Cenoz y José F. Valencia. Bilbao: Universidad del País Vasco, 1996. 155-75.

Brown, Penelope, y Stephen C. Levinson. Politeness: Some Universals in Language Usage. Cambridge: Cambridge UP, 1987.

Calvi, Maria Vittoria. Didattica di lingue affini: spagnolo e italiano. Milán: Edizioni Angelo Guerini, 1995.

Calvi, Maria Vittoria. "Aprendizaje de lenguas afines: español e italiano". Revista electrónica de didáctica ELE 1 (2004). 13 de enero de 2019. <http:// www.educacion.gob.es/redele/revista RedEle/2004/segunda.html>.

César Vera, Yalena Carolina. La cibercortesía en Chile y Venezuela: distancia y acercamiento. 2013. Universidad de Los Andes. Tesis de máster. 13 de enero de 2019. <http://www.saber.ula.ve/handle/123456789/36664>. 
Chen, Xueuei, Lu Yang, Qiang Chang y Zohreh Eslami. "Pragmatic Usage in Academic Email Requests: A Comparative and Contrastive Study of Written DCT and Email Data". Lingue e Linguaggi 13 (2015): 75-85.

Contreras Fernández, Josefa. “¿Hay diferencia en las estrategias de atenuación en los correos electrónicos españoles y alemanes?”. Miradas multidisciplinares a los fenómenos de cortesía y descortesía en el mundo bispánico. Eds. Julio Escamilla y Grandfield Henry. Barranquilla: Universidad del AtlánticoPrograma EDICE, 2012. 451-71.

Diccionario de términos clave de ELE. Instituto Cervantes, 1997-2020. 13 de enero de 2019. <https://cvc.cervantes.es/ensenanza/biblioteca_ele/diccio_ele/ indice.htm>.

Doquin de Saint Preux, Anna. "Algunas consideraciones respecto a la metodología de investigación en sociolingüística y pragmática: comentario al artículo de Carlos de Pablos Ortega". Revista Nebrija de Linguiistica Aplicada a la enseñanza de lenguas 10.5 (2011): 54-61. 13 de enero de 2019. $<$ http://www.nebrija.com/revista-linguistica/files/revistasPDF/526a47c f4c60f_revista_completa_10.pdf $>$.

Dumitrescu, Domnita. "Imagen y (des)cortesía en la comunicación académica por ordenador: reflexiones en torno a un caso concreto". Cortesía y conversación: de lo escrito a lo oral (III Coloquio internacional del Programa EDICE). Eds. Antonio Briz, Antonio Hidalgo, Marta Albelda, Josefa Contreras y Nieves Hernández. Valencia: Universidad de Valencia, 2008. 437-67.

Escandell Vidal, M. ${ }^{a}$ Victoria. "Los fenómenos de interferencia pragmática". Didáctica del Español como Lengua Extranjera: Expolingua 3 (1996): 95-109.

Fernández Amaya, Lucía. "Teaching Culture: Is it Possible to Avoid Pragmatic Failure?". Revista Alicantina de Estudios Ingleses 21 (2008): 11-24. 13 de enero de 2019. <http://rua.ua.es/dspace/handle/10045/10393>.

Galindo Merino, Mar. "La transferencia pragmática en el aprendizaje de ELE". La competencia pragmática y la enseñanza del español como lengua extranjera: Actas del XVI Congreso Internacional de ASELE. Eds. Alfredo Álvarez y otros. Oviedo: Universidad de Oviedo, 2005. 289-97. 13 de enero de 2019. $<$ http://cvc.cervantes.es/ensenanza/biblioteca_ele/asele/pdf/16/16_0289. pdf>.

Hauge, Eline Kårtvedt. La cortesía verbal y la imagen pública: un análisis pragmalingüístico de la petición en noruego y en español argentino. 2013. Universidad de Oslo. Tesis de máster. 13 de enero de 2019. <https://www.duo. uio.no/handle/10852/37067>. 
Haverkate, Henk. "Estrategias de cortesía: análisis intercultural”. Actas del VII Congreso ASELE. Lengua y Cultura en la Enseñanza del Español a Extranjeros. Eds. Ángela Celis y José Ramón Heredia. Almagro: Universidad de Cuenca, 1996. 45-57. 13 de enero de 2019. <http://cvc.cervantes.es/ensenanza/biblioteca_ele/asele/pdf/07/07_0043.pdf>.

Jimeno Patrón, Josefa. El correo electrónico de petición en el ámbito académico estudio contrastivo alemán/español. 2012. Universidad Antonio de Nebrija. Tesis de máster inédita.

López Cordero, Mario. "La (des)cortesía en la comunicación mediante ordenador: los correos electrónicos entre profesor y alumno". Actas del II Congreso de Hispanistas y Lusitanistas Nórdicos. Eds. Lars Fant, Johan Falk, María Bernal y Ferrán Ferrando. Estocolmo: Universidad de Estocolmo, 2009, 43-53.

López Díaz, Carol. Estudio sociopragmático sobre el acto de babla directivo de la petición en el español de Chile. 2012. Universidad de Valladolid. Tesis doctoral inédita. 13 de enero de 2019. <http://uvadoc.uva.es/bitstream/10324/ 2926/1/TESIS330-130604.pdf>.

Mackey, Alison, y Susan M. Gass. Data Elicitation for Second and Foreign Language Research. New York: Routledge, 2007.

Nicholls, Chelsea. El conocimiento de normas pragmáticas en las peticiones electrónicas: un estudio comparativo entre hablantes de español como lengua nativa, lengua heredada y lengua extranjera. 2009. Universidad de Arizona. Tesis de máster inédita. 13 de enero de 2019. <http://arizona.openrepository. com/arizona/bitstream/10150/193232/1/azu_etd_10457_sip1_m.pdf>.

Nikleva, Dimitrinka. "La cortesía en los correos electrónicos de estudiantes universitarios como parte de la competencia pragmático-discursiva". Spanish in Context 12.2 (2015): 280-303.

Nikleva, Dimitrinka, y Pilar Núñez. "El correo electrónico como género discursivo: percepciones y habilidades para su composición en estudiantes universitarios". Revista Española de Lingüística Aplicada 26 (2013): 385407.

Nuzzo, Elena, y Stefano Rastelli. “«Didattica acquisizionale» e cortesia linguistica in italiano L2". Cuadernos de Filología Italiana 16 (2009): 13-30.

Robles Garrote, Pilar. "La cortesía verbal en la interacción asincrónica académica: análisis contrastivo en inglés, español e italiano". Estudios de Linguiistica Aplicada 60 (2014): 117-39. 13 de enero de 2019. <https://ela.enallt.unam.mx/index.php/ela/article/view/5/5>. 
Robles Garrote, Pilar. "La transferencia pragmática en el aprendizaje de lenguas afines: análisis de interacción escrita en español e italiano". Círculo de Lingiuistica Aplicada a la Comunicación 68 (2016): 322-49. 13 de enero de 2019. $<$ http://revistas.ucm.es/index.php/CLAC/article/view/54533/49812>.

Robles Garrote, Pilar. Perspectivas de análisis pragmático de correos electrónicos de petición: estudio contrastivo en italiano y español L1/L2. 2017. Universidad Antonio de Nebrija. Tesis doctoral inédita.

Robles Garrote, Pilar, y Manuela del Carmen Rojas. "La validación por juicio de expertos: dos investigaciones cualitativas en Lingüística Aplicada". Revista Nebrija de Linguiistica aplicada a la enseñanza de Lenguas 18 (2015). 13 de enero de 2019. <https://www.nebrija.com/revista-linguistica/files/articulosPDF/articulo_55002aca89c37.pdf>.

Shim, Young-Sook. "International Faculty Perceptions of Requestive Emails by Korean University Students". Multimedia-Assisted Language Learning 16.4 (2013): 111-31. 13 de enero de 2019. <http://journal.kamall.or.kr/ wp-content/uploads/2014/01/Shim-16-4-5.pdf>.

Sifianou, Maria. Politeness Phenomena in England and Greece: A Cross-cultural Perspective. Oxford: Oxford UP, 1992.

Steele, Clarissa R. The Effect of Study Abroad on the Acquisition of Pragmatics: A Comparison of Requests Made by L2 Spanish Graduate Students. 2006. Bowling Green State University (Ohio). Tesis de máster inédita. 13 de enero de 2019. <https://etd.ohiolink.edu/pg_10?::NO:10:P10_ETD_SUBID: 48401>.

Toledo Vega, Gloria. Adquisición pragmática en aprendientes de español como lengua extranjera. 2012. Universidad de Valladolid. Tesis doctoral inédita. 13 de enero de 2019. <http://uvadoc.uva.es/bitstream/10324/1114/6/TESIS194-120828.pdf>.

Tseng, Chia-Ti Heather. "E-politeness: An Analysis of Taiwanese EFL Learners' Email Discourse on Request Strategies". International fournal for 21st Century Education, Special Issue: Language Learning and Teaching 3 (2016): 35-62.

Turnbull, William. "An Appraisal of Pragmatic Elicitation Techniques for the Social Psychological Study of Talk: The Case of Refusals". Pragmatics 11 (2001): 31-61. 